\title{
The Effect of Using Bone Marrow Mesenchymal Stem Cells Versus Platelet Rich Plasma on the Healing of Induced Oral Ulcer in Albino Rats
}

\author{
Fatma Mohamed Rashed ${ }^{1}$, Olfat Mohamed GabAllah ${ }^{2}$, Sarah Yasser AbuAli ${ }^{2}$, Mohamed Taha Shredah ${ }^{1}$ \\ ${ }^{\text {I} O r a l ~ B i o l o g y ~ D e p a r t m e n t, ~ F a c u l t y ~ o f ~ D e n t i s t r y, ~ D a m a n h o u r ~ U n i v e r s i t y, ~ D a m a n h o u r, ~ E g y p t ~}$ \\ ${ }^{2}$ Oral Biology Department, Faculty of Dentistry, Tanta University, Tanta, Egypt
}

Background and Objectives: Oral ulceration is one of the most common debilitating condition that affects the oral cavity. In this study, the effect of locally injected platelet rich plasma (PRP) and bone marrow-derived mesenchymal stem cells (BMSCs) on the healing of oral ulcer was investigated.

Methods and Results: An ulcer was induced in buccal mucosa of rats by using $5 \mathrm{~mm}$ biopsy punch followed by application of cotton swab soaked with formocresol for 60 sec. The ulcer was left untreated in the control group, treated with intralesional injection of PRP, or isolated cultured BMSCs. Data were analyzed clinically, histologically and immunohistologically on day 3, 5, 7 and 10. BMSCs group showed smaller ulcer area throughout the whole experimental period than the other groups with complete resolution of the ulcer on day 10, unlike the control group. However, there was no significant difference with PRP, on day 5, 7 and 10, regarding clinical ulcer size. BMSCs group showed better histological results regarding the rate of epithelial cell migration, the number of inflammatory cells, thickness and organization of collagen fibres and the number of blood vessels, with complete re-epithelization on day 10. BMSCs group showed a greater number of anti-PCNA positive nuclei throughout the whole experimental period than the other groups except on day 5, PRP had higher mean numbers of anti-PCNA positive nuclei in both tissues.

Conclusions: Both PRP and BMSCs accelerate wound healing and enhance the quality of the healing tissue with the latter being slightly more effective and faster.

Keywords: Formocresol, Induced oral ulcer, Mesenchymal stem cells, Platelet rich plasma, Rats, Wound healing

Received: August 25, 2018, Revised: January 7, 2019,

Accepted: January 11, 2019, Published online: February 28, 2019

Correspondence to Fatma Mohamed Rashed

Oral Biology Department, Faculty of Dentistry, Damanhour University, Damanhour 22511, Egypt

Tel: +20-45-336-8069, Fax: +20-45-3358637

E-mail: fatma.rashed@dnt.dmu.edu.eg

(c) This is an open-access article distributed under the terms of the Creative Commons Attribution Non-Commercial License (http://creativecommons.org licenses/by-nc/4.0/), which permits unrestricted non-commercial use, distribution, and reproduction in any medium, provided the original work is properly cited.

Copyright (c) 2019 by the Korean Society for Stem Cell Research

\section{Introduction}

Oral ulceration is one of the most common debilitating and widespread conditions that affect the oral cavity. It is a major concern for public health, as it affects the patient's quality of life dramatically. An oral ulcer occurs consequently to epithelial damage that is a result of a wide range of injuries. They can be caused by trauma, infection, immune imbalance, allergic reactions, burns, use of chemical drugs, chemotherapy and radiotherapy (1). Owing to the rich innervations of the oral mucosa, the prolonged and painful ulceration may present significant problems to the patient, such as difficulty in eating, speaking, swallowing and maintaining good oral hygiene. On the other 
hand, due to the good vascularity of the oral tissues, most oral ulcers heal relatively quickly. However, in case of severe, recurrent or chronic ulcers, general treatment modalities are needed to restore the function and physiology of the injured tissue, this can include the application of steroids, tetracycline, analgesics, and antiseptic mouthwashes, among others (2). These therapies were recommended for the symptomatic management to reduce pain and aid healing of lesions; however, long-term frequent use of these medications have many side effects, including acne, rashes, sweating, weight gain and increased blood glucose levels. In addition, steroids may affect bones and cause existing infections to get worse or allow new infections to occur, or cause allergic and hypersensitivity reactions (3).

Regenerative medicine concept is emerging as an alternative to the conventional line of treatment in wound healing. Scientific advances in understanding the molecular mechanism of wound healing helped in developing the concept of administration of growth factors directly to the wound as part of its care (4). Platelet rich plasma (PRP) and mesenchymal stem cells (MSCs) represent a biological pool of wide range of growth factors and cytokines that are essential for optimum wound healing $(5,6)$.

PRP is an autologous concentration of human platelets above baseline in a small volume of plasma. The properties of PRP are based on the production and release of multiple growth and differentiation factors (7). PRP gel is used widely in promoting the healing of chronic cutaneous non healing wounds (8). Also, it is used the field of surgery for the treatment of a variety of hard tissue defects, as it accelerates bone formation (9).

On the other hand, mesenchymal stem cells is emerging as new potential clinical application in wound healing. BMSCs are fibroblast-like cells that are characterized by combinations of cell surface markers and by their ability to differentiate into diverse cell types (10). BMSCs has been widely used in chronic wounds healing extensively (11).

Accordingly, we hypothesized that using both PRP and BMSCs will enhance oral ulcer healing, however, we aimed to compare the healing effect of both remedies through clinical, histological and immunohistochemical evaluation.

\section{Materials and Methods}

\section{Experimental animals and ulcer induction}

Male albino rats 8 10 weeks of age, weighing 250 300 g were obtained and housed in the animal house of faculty of medicine, physiology department, Alexandria Univer- sity. They were maintained in plastic cages with sawdust-covered floors at a temperature of $24^{\circ} \mathrm{C}$ in a darklight cycle of 12 hours with free access to water and commercial food. The experimental protocol was designed in accordance with the guidelines for the responsible use of laboratory animals in research (12). All experimental procedures were approved by the ethical committee at Tanta University.

Rats were anaesthetized with an intramuscular injection of ketamine hydrochloride $10 \%$ and xylazine hydrochloride $2 \%$ (AMOUN, Egypt) at a dosage of $0.06 \mathrm{ml} / 100 \mathrm{~g}$ and $0.03 \mathrm{ml} / 100 \mathrm{~g}$, respectively. A homogeneous standardized circular oral cheek ulcer was obtained using $5 \mathrm{~mm}$ biopsy punch (13), followed by perpendicular application of a flexible swab with a cotton tip soaked in formocresol for 60 s (14).

Sixty rats were randomly divided into three groups $(\mathrm{n}=20)$.

I) Control group: ulcers were left without any treatment.

II) PRP group: ulcers were treated with local injection of $0.1 \mathrm{ml}$ of freshly prepared PRP solution at five points, four points circumferentially around the margins and the fifth point in the ulcer centre, using a 27-gauge syringe, immediately after ulcer induction. The injection was $2 \sim 3$ $\mathrm{mm}$ deep and was done slowly to allow proper diffusion of solution in the loose connective tissue in the submucosa of cheeks.

III) BMSCs group: ulcers were treated with local injection of the isolated BMSCs solution $\left(1 \times 10^{6}\right.$ cells suspended in $0.1 \mathrm{ml}$ of complete media) (15) at five points, four points circumferentially around the margins and the fifth point in the ulcer centre, using a 27-gauge syringe, immediately after ulcer induction. The injection was $2 \sim 3$ $\mathrm{mm}$ deep and was done slowly to allow proper diffusion of solution in the loose connective tissue in the submucosa of cheeks.

\section{PRP preparation}

Blood was drawn directly from heavily anaesthetized rat by cardiac puncture and injected in a sodium citrate tube $3.2 \%$ for separation of PRP then centrifuged at 800 RPM for $15 \mathrm{~min}$. The average platelet count was $647 \times 10^{3} / \mu \mathrm{L}$.

\section{Culture, harvesting, and characterization of BMSCs}

Bone marrow was flushed from both femurs of a rat after its euthanization with complete culture medium. Complete medium was composed of DMEM-LG, 10\% FBS, $1 \%$ L-Glutamine \& 1\% pen/strept (Lonza Bioproducts, Belgium). Flushed bone marrow was centrifuged at 1200 RPM for $8 \mathrm{~min}$. Cell pellets were resuspended in $5 \mathrm{ml}$ 

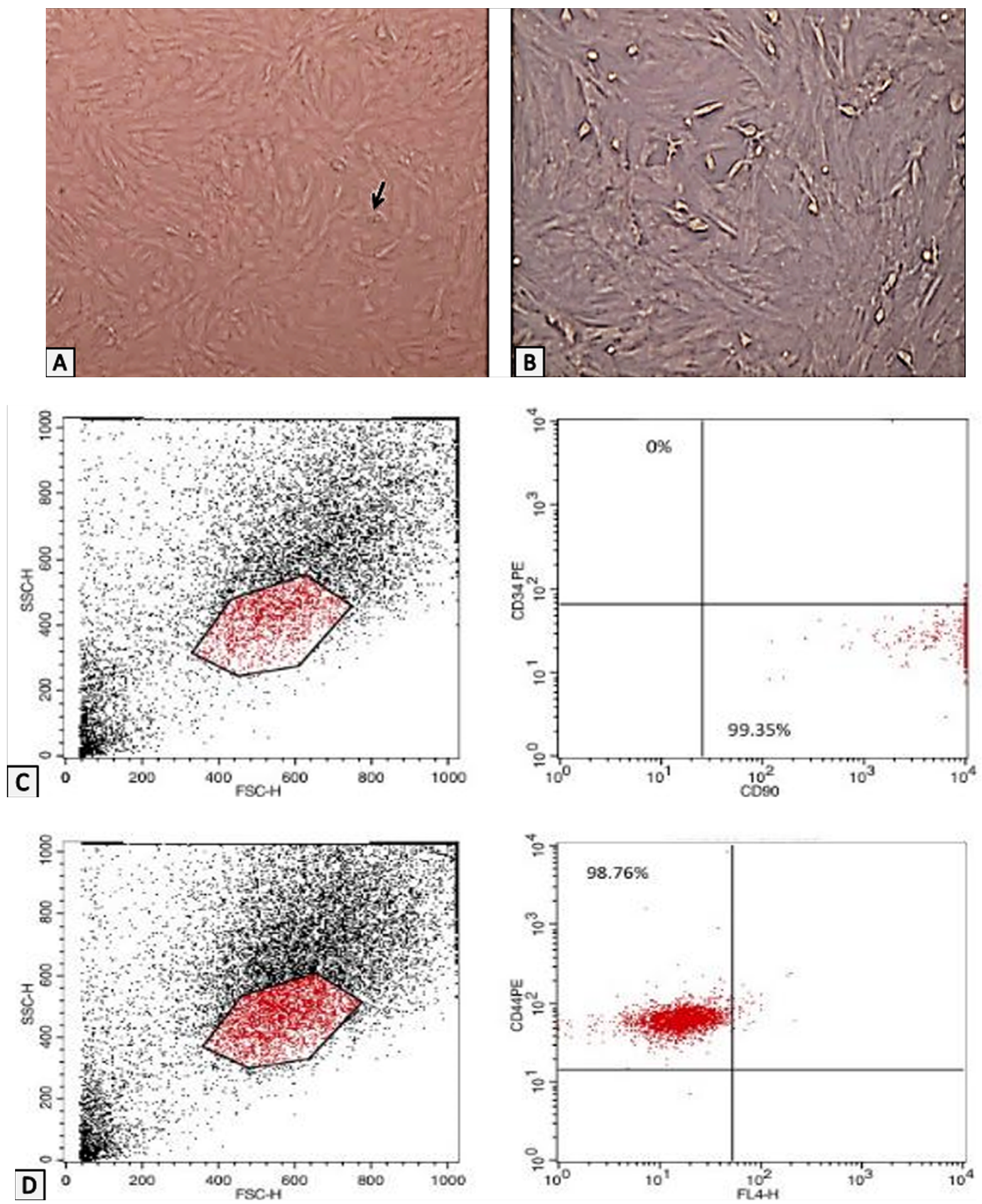

Fig. 1. Morphological characteristics of BMSCs using Phase-contrast inverted microscope. (A) Passage $2,80 \%$ confluent showing homogenously fibroblastic like cell monolayer $(\times 100)$. (Black arrows) showing cells undergoing mitosis. (B) Higher magnification of cells $(\times 400)$ passage 2 showing spindle shaped fibroblast like cells with processes forming a monolayer. (C \& D) FACS analysis for BMSCs at passage 3 demonstrated that $98.76 \%$ and $99.35 \%$ of the cultured cells expressed the mesenchymal CD44 and CD90 markers respectively, while they were negative for CD34 hematopoietic marker. These results indicated that relatively purified MSCs were isolated. 
complete media, transferred into T-25 flask and cultured in humidified $5 \% \mathrm{CO}_{2}$ incubator at $37^{\circ} \mathrm{C}$. At passage 3 cells were harvested by trypsinization then counted for transplantation.

Cells were characterized using cell surface markers by fluorescence-activated cell sorting (FACS) analysis on a FACS caliber flow cytometer equipped with Cell Quest software (Becton Dickinson). The cells were stained with different fluorescently labelled monoclonal antibodies (mAb). MSCs were characterized for CD44, CD90 (Abcam, UK) as a positive markers, in addition to CD34 (Abcam, UK) (hematopoietic surface markers).

\section{Evaluation of ulcer healing clinically, histologically and Immunohistochemically}

Clinical analysis of the healing process was assessed through standardized photographs at day 3, 5, 7 and 10 after ulcer induction and ulcer area was measured in $\mathrm{mm}^{2}$ using the free hand selection tool ImageJ software (ImageJ 1.48s, Wayne Rasband, National Institute of Health, USA).

Tissue sections were stained using H\&E stain (for general examination) and Gomori trichrome stain (for demonstration of collagenous components).

Finally, Images of the immunostained sections were analyzed for expression of anti-PCNA antibodies using the Image J software. The areas showing the brown DAB immunostaining were manually counted using the multi-point tool. The number of anti-PCNA-positive in epithelial and connective tissue cells were counted using a magnification of $\times 400$ in 5 measuring fields in each specimen, and mean value was calculated. Immunohistochemical control (IHC) was stained without the primary antibody.

\section{Statistical evaluation}

Statistical analysis was performed blindly using SPSS version 16.0 (SPSS, Chicago, IL, USA). Quantitative data from imageJ analysis were described using mean and standard deviation. Data of clinical and immunohistochemical staining of different studied groups were compared and analyzed using analysis of variance (ANOVA) followed by Tukey's post hoc test for pairwise comparisons. Significance of the obtained results was judged at $\mathrm{p} \leq 0.05$.

\section{Results}

\section{Flow-cytometry characterization}

FACS analysis for BMSCs at passage 3 demonstrated that $98.76 \%$ and $99.35 \%$ of the cultured cells expressed the mesenchymal CD44 and CD90 markers respectively, while they were negative for CD34 hematopoietic marker (Fig. 1).

\section{Clinical/macroscopic analysis}

Clinically the rats of both PRP and stem cell groups showed substantial extra-oral swelling after administration of intralesional injection of PRP and stem cells. This swelling began to decrease gradually after day 3 compared to the control group which showed minimal swelling from the beginning. In all groups, on day 0 , the presence of ulceration covered with a whitish-yellow necrotic membrane was clinically observed. During the first 3 days, the injuries in the cheek mucosa of the animals were clinically visible and were crateriform and red in all groups. From days 5 to 7, the size of the injuries decreased in all groups; however, in the control group, the ulcer had irregular bor-
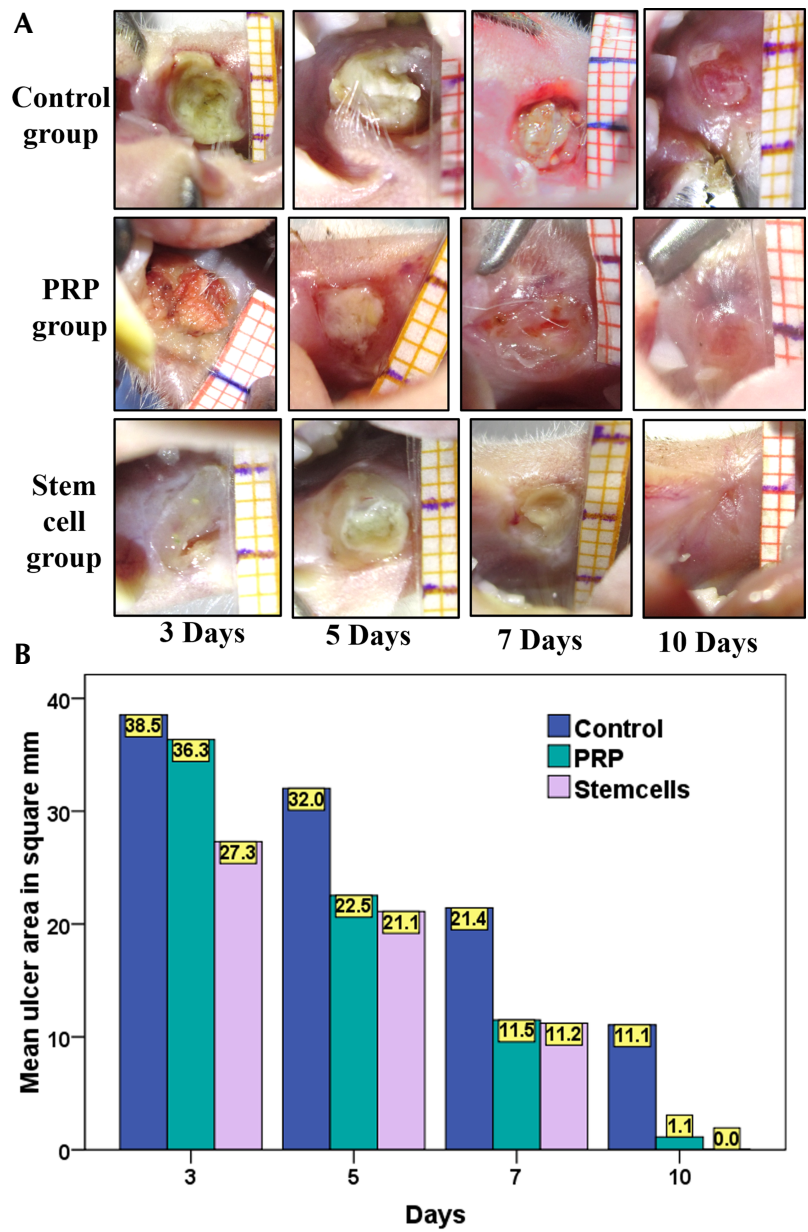

Fig. 2. (A) Clinical view of buccal ulcer of control group, PRP group, stem cell group at day 3, 5, 7 and 10 after ulcer induction. (B) Column chart representing the mean of ulcer surface area in $\mathrm{mm}^{2}$ in the control, PRP and stem cell group in the different time intervals (PRP, Platelet rich plasma). 
ders with a whitish halo surrounding the reminiscent injury. On the $10^{\text {th }}$ day, the ulcer of the BMSCs was healed. Also, in the PRP group the ulcer was considered healed; however the epithelial covering of the ulcer was thin. On the other hand the ulcer of the control group was still clinically present (Fig. 2).

There was a significant difference between groups regarding the reduction in the ulcer surface area in all intervals. However, there was no significant difference between control and PRP groups on days 3. Although, there was no significant difference between PRP and BMSCs groups on days 5, 7 and 10, there was a significant reduction of the ulcer area of BMSCs group in comparison with the PRP group. Similarly, BMSCs group showed a significantly smaller ulcer area than the control group throughout the whole experimental period (Fig. 2, Table 1).

\section{H\&E histological results}

On day 3, wounds of the control group were displaying extensive ulcerations. The epithelial cells at the wound margin were oedematous. The wounds of the PRP group exhibited deep epithelial cells migration at the wound margin. Also, in the BMSCs group, there was epithelial proliferation and migration at the wound margin evidenced by increased mitotic figures in the epithelial cells.

On day 5 and 7, the wounds of the control group displayed delayed epithelization and migration above the thick underlying inflamed granulation tissue. In the RPR group, the migration of the wound epithelium had progressed across the wound bed, but the centre of the wound space was still open. Also, BMSCs group displayed epithelial proliferation and migration toward the wound.

On day 10, reepithelization was incomplete in the control group. In the PRP group, the wound area was covered by an atrophic, thin layer of stratified squamous epithelium with thin keratin layer and flat rete ridges. However, the BMSCs group showed wound closure with almost complete reepithelization, the epithelium displayed maturation and moderate thickness of keratin layer (Fig. 3).

\section{Trichrome histological results}

In the control group at day 3 after ulcer induction, collagen fibres at the centre of the lesion were thin and distributed in a haphazard manner. They were surrounded by numerous inflammatory cells. The PRP group displayed a discrete deposition of thin, disorganized collagen fibres was observed, at the centre of the lesion. Whereas in the BMSCs the granulation tissue underneath the epithelial wound margin displayed moderate amount of collagen fibres. It was infiltrated by a moderate intensity of inflammatory cells and numerous variable sized blood vessels.

On day 5 and 7, the control group displayed the granulation tissue with inflammatory cell infiltrate, some blood vessels and collagen fibres that were moderately thick and randomly distributed. In the PRP group, a thick granulation tissue with inflammatory cells infiltration at the surface of the wound. While the deeper layers showed less inflammation with fine interlacing collagen fibres, numerous dilated blood vessels. In the BMSCs group, deeply stained collagen bundles were seen arranged parallel to epithelial surface beneath the moderately inflamed granulation tissue. Well organized collagen bundles with variable numbers of fibroblast cells and the new blood vessels were clearly seen.

On day 10, the control group displayed moderate inflammatory cell infiltration, some blood vessels and colla-

Table 1. The mean surface area of ulcer in $\mathrm{mm}^{2}$ in each time interval within each group

\begin{tabular}{|c|c|c|c|c|c|c|}
\hline & & \multicolumn{5}{|c|}{ Mean ulcer area/mm² } \\
\hline & & 0 days & 3 days & 5 days & 7 days & 10 days \\
\hline Control & & $25.01 \pm 0.0$ & $38.52 \pm 4.22(154 \%)$ & $32.01 \pm 2.80(128 \%)$ & $21.43 \pm 3.25(85 \%)$ & $11.06 \pm 5.79$ \\
\hline PRP & & $25.01 \pm 0.0$ & $36.33 \pm 2.96(145 \%)$ & $22.54 \pm 6.41(90 \%)$ & $11.50 \pm 5.69(46 \%)$ & $1.14 \pm 0.71 \quad(4 \%)$ \\
\hline BMSCs & & $25.01 \pm 0.0$ & $27.29 \pm 4.78(109 \%)$ & $21.11 \pm 3.09(84 \%)$ & $11.21 \pm 2.21(44 \%)$ & $0.00 \pm 0.00(0 \%)$ \\
\hline ANOVA & $\mathrm{F}$ & 0.16 & 10.72 & 8.98 & 10.59 & 15.58 \\
\hline Tukey HSD & $p$-value & 0.85 & $\begin{array}{l}\quad 0.002 \\
\text { (Control, PRP) } \\
\text { (Control, BMSCs) }^{\mathrm{a}} \\
\text { (PRP, Stem cells) }^{\mathrm{a}}\end{array}$ & $\begin{array}{l}\quad 0.004 \\
\text { (Control, PRP) }^{\mathrm{a}} \\
\text { (Control, BMSCs) }^{\mathrm{a}} \\
\text { (PRP, BMSCs) }\end{array}$ & 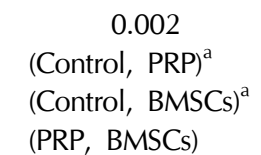 & $\begin{array}{l}\quad 0.00 \\
\text { (Control, PRP) }^{\mathrm{a}} \\
\text { (Control, BMSCs) }^{\mathrm{a}} \\
\text { (PRP, BMSCs) }\end{array}$ \\
\hline
\end{tabular}

${ }^{a}$ The mean difference is significant at $\mathrm{p} \leq 0.05$ level.

Values are given as mean $\pm \mathrm{SD}$, in $\mathrm{mm}^{2}$.

PRP: Platelet rich plasma, BMSCs: Bone marrow mesenchymal stem cells. 


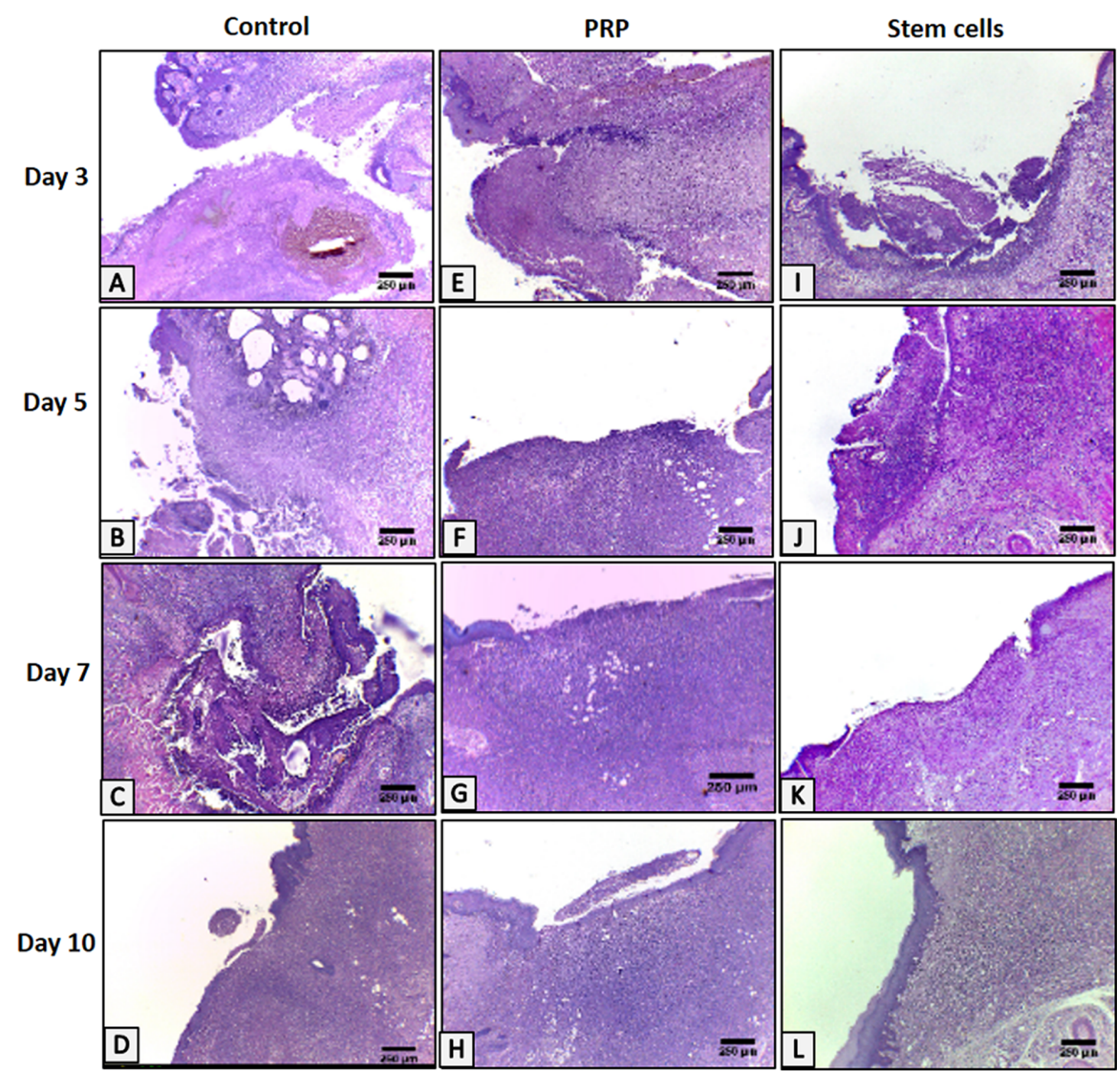

Fig. 3. Representative histological images of ulcer healing in the control group $(A \sim D)$, the PRP group $(E \sim H)$ and the BMSCs group $(I \sim L)$. Control group: Minimal epithelial migration above the dense granulation tissue on days 3 (A), 5 (B) and 7 (C). Persistence of a small ulcer area in epithelium with moderately inflamed underlying connective tissue on day 10 (D). PRP group: Deep epithelial cells migration at the wound margin above the dense granulation tissue on days $3(\mathrm{E}), 5(\mathrm{~F})$ and $7(\mathrm{G})$. Complete wound closure on day $10(\mathrm{H})$, the wound area is covered by thin layer of stratified squamous epithelium with thin keratin layer and flat rete ridges and the underlying connective still showing signs of moderate inflammation. BMSCs group: Epithelial proliferation and migration at the wound margin with moderate density of granulation tissue filling the wound core and has inflammatory cells infiltration on days 3 (I), 5 (J) and 7 (K). Full wound closure with complete re-epithelization on day 10 (L), the epithelium at the wound area showing maturation with moderate thickness of keratin layer and the underlying connective still showing signs of moderate inflammation. Haematoxylin-eosin staining; magnification, $40 \times$. Scale bar $=250 \mu \mathrm{m}$ (PRP, Platelet rich plasma).

gen fibres that were moderately thick and randomly distributed. In the PRP group, thick collagen fibres perpendicular to the surface epithelium and some inflammatory cells were seen. It also contained many blood vessels with extravasated red blood cells were seen. While in the BMSCs group the connective tissue started to regain its normal architecture with more organized collagen fibres, many fibroblasts, high vascularity and mild inflam- matory cells infiltration (Fig. 4).

\section{Immunohistochemical results}

On day 5 and 7, the number of anti-PCNA positive nuclei in epithelial tissue of PRP group was significantly higher than the control group. Interestingly, BMSCs group showed a greater number of anti-PCNA positive nuclei in epithelial cells throughout the whole experimental period 


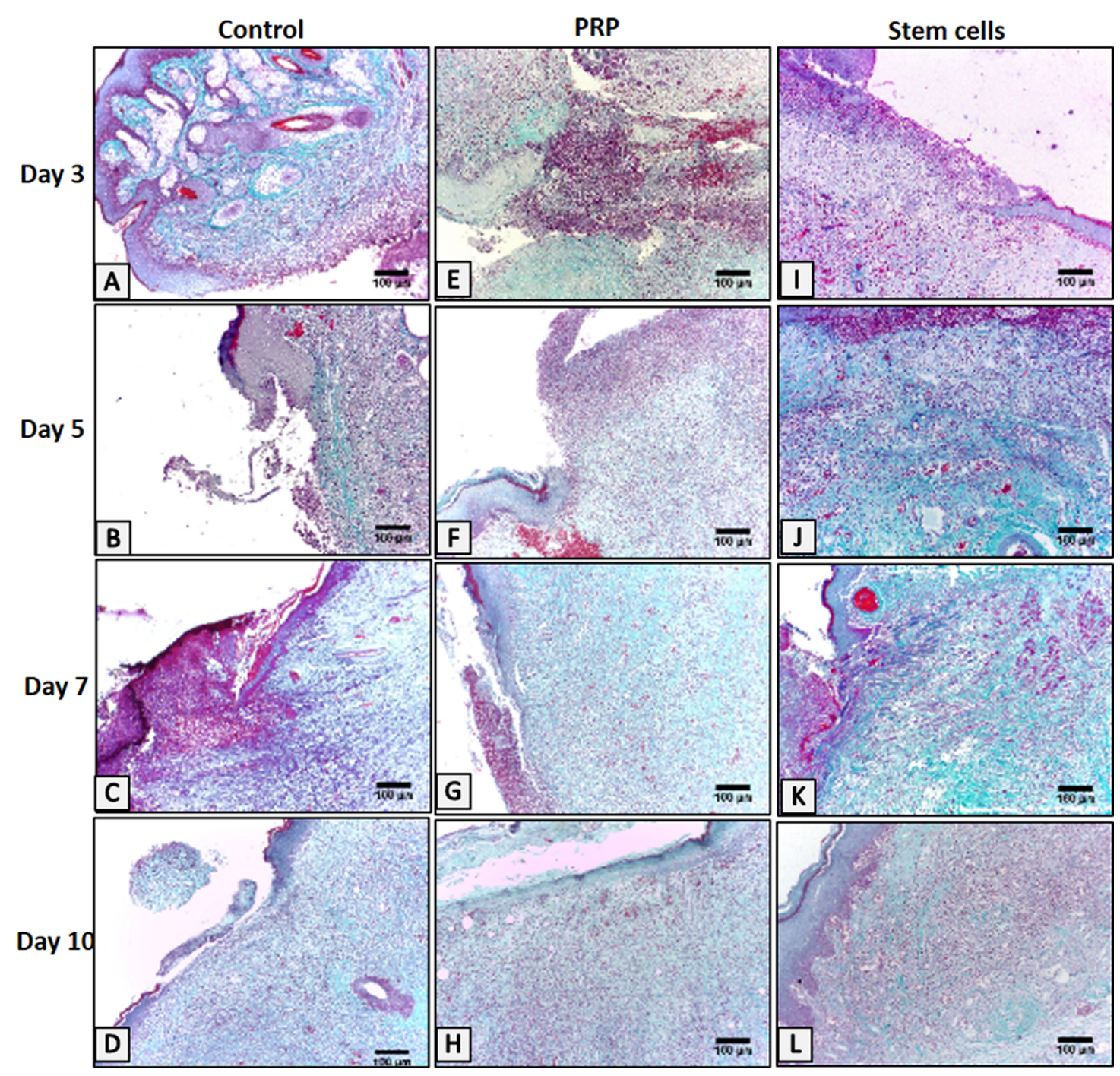

Fig. 4. Representative histological images of ulcer healing in the control group $(A \sim D)$, the PRP group $(E \sim H)$ and the BMSCs group $(I \sim L)$. Control group: Collagen fibres at the wound area are thin and distributed in haphazard manner surrounded by numerous inflammatory cells, small new blood vessels and extravasated red blood cells on days 3 (A) and 5 (B). Combination of fine and moderately coarse collagen fibres that are randomly distributed with moderate inflammatory cells infiltration in addition to numerous small blood vessels on days 7 (C) and day 10 (D). PRP group: The central granulation tissue consists of fine interlacing collagen fibres, numerous dilated blood vessels and extravasated red blood cells on days 3 (E) and 5 (F). The connective tissue exhibiting thick collagen fibres with variable number of fibroblasts and numerous blood vessels on days $7(\mathrm{G})$ and $10(\mathrm{H})$. BMSCs group: moderately arranged interlacing collagen fibres running somewhat parallel to the surface epithelium, neovascularization and discrete inflammatory infiltration on days 3 (I) and 5 (J). The connective tissue starting to regain its normal architecture with more organized collagen fibres, many fibroblasts, high vascularity and mild inflammatory cell infiltration on days $7(\mathrm{~K})$ and10 (L). Trichrome staining; magnification, $100 \times$. Scale bar $=100 \mu \mathrm{m}(\mathrm{PRP}, \mathrm{Platelet}$ rich plasma).

compared to other groups except on day 5 where PRP group had higher mean numbers of anti-PCNA positive nuclei. Regarding PCNA expression in the underlying lamina propria cells, there was a significant increase of the marker expression between the control and PRP groups in all intervals except on day 3. There was a significantly higher expression of PCNA between PRP and BMSCs groups on day 3 and 7. On the other hand, there was no significant difference between PRP and BMSCs groups on day 5 and 10 although PRP scored higher levels on day 5. However, BMSCs group showed a greater number of anti-PCNA positive nuclei throughout the whole experimental period than the control (Fig. 5, 6, Table 2, 3). 

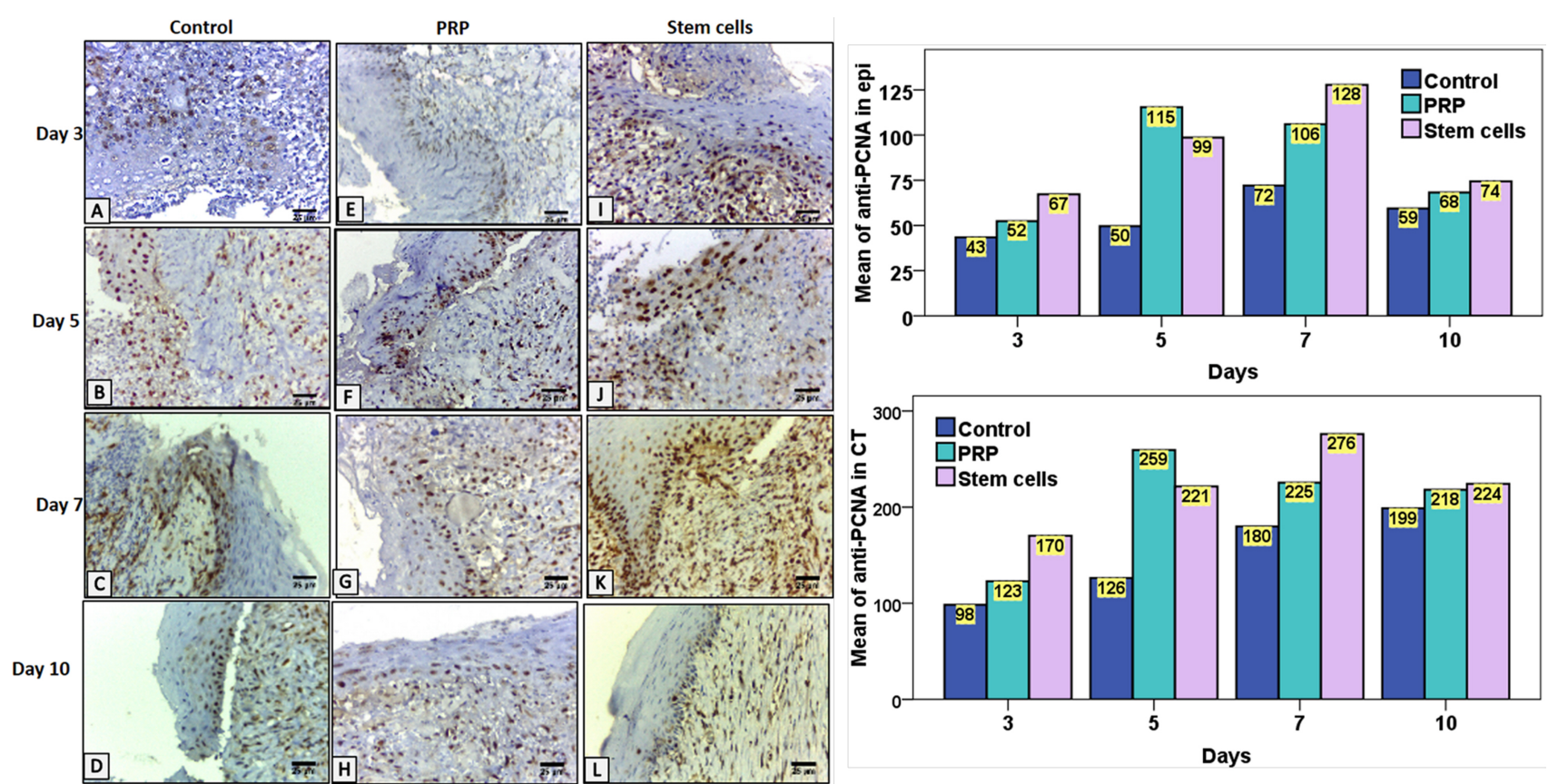

Fig. 5. Left image, representative images of immunolocalization at wound area in the control group $(A \sim D)$, the PRP group $(E \sim H)$ and the BMSCs group $(\mathrm{I} \sim \mathrm{L})$. In the control group, relatively smaller number of nuclei showed immunoreactivity, in all the days compared to the PRP and BMSCs group. The BMSCs group showed a slightly higher number of positive nuclei than PRP group at the basal and suprabasal cells of epithelium and in some keratinocytes in migrating epithelium at ulcer surface. Similarly, the connective tissue cells, as well as endothelial cells lining the blood vessels of the BMSCs group, expressed a greater number of nuclear positive cells compared to the PRP and the control group. Anti-PCNA antibodies; magnification, $400 \times$. Scale bar $=25 \mu \mathrm{m}$ (PRP, Platelet rich plasma). Right image, Column chart representing the mean of anti-PCNA antibodies positive nuclei in epithelial tissue (epi) in the control, PRP and stem cell groups in the different time intervals. Column chart representing the mean of anti-PCNA antibodies positive nuclei in connective tissue (CT) in the control, PRP and stem cell group in the different time intervals.

Table 2. The mean number of anti-PCNA positive nuclei in epithelial tissue in each group within same time interval

\begin{tabular}{|c|c|c|c|c|c|}
\hline & & \multicolumn{4}{|c|}{ Mean of anti-PCNA positive nuclei in epithelial tissue } \\
\hline & & 3 days & 5 days & 7 days & 10 days \\
\hline Control & & $43.40 \pm 7.82$ & $49.60 \pm 8.26$ & $67.80 \pm 3.96$ & $73.00 \pm 4.52$ \\
\hline PRP & & $52.40 \pm 8.79$ & $115.40 \pm 15.12$ & $106.00 \pm 11.06$ & $75.40 \pm 5.17$ \\
\hline BMSCs & & $67.20 \pm 7.72$ & $98.60 \pm 7.82$ & $127.80 \pm 13.08$ & $86.40 \pm 5.50$ \\
\hline \multirow[t]{2}{*}{ ANOVA } & $\mathrm{F}$ & 10.92 & 48.91 & 44.71 & 9.86 \\
\hline & p-value & 0.002 & $\leq 0.001$ & $\leq 0.001$ & 0.003 \\
\hline \multirow[t]{3}{*}{ Tukey HSD } & & (Control, PRP) & $(\text { Control, PRP) })^{\mathrm{a}}$ & $(\text { Control, PRP) })^{\mathrm{a}}$ & (Control, PRP) \\
\hline & & $(\text { Control, BMSCs })^{a}$ & $(\text { Control, BMSCs })^{\mathrm{a}}$ & $(\text { Control, BMSCs })^{a}$ & (Control, BMSCs) ${ }^{\mathrm{a}}$ \\
\hline & & $(\mathrm{PRP}, \mathrm{BMSCs})^{\mathrm{a}}$ & $(\mathrm{PRP}, \mathrm{BMSCs})^{\mathrm{a}}$ & $(\mathrm{PRP}, \mathrm{BMSCs})^{\mathrm{a}}$ & $(\mathrm{PRP}, \mathrm{BMSCs})^{\mathrm{a}}$ \\
\hline
\end{tabular}

${ }^{\mathrm{a}}$ The mean difference is significant at $\mathrm{p} \leq 0.05$ level.

Values are given as mean \pm SD.

PRP: Platelet rich plasma, BMSCs: Bone marrow mesenchymal stem cells.

\section{Discussion}

The process of ulcer healing is a genetically programmed series of biologic events that normally integrates complex biological and molecular mechanisms, such as cell migration and proliferation, along with extracellular ma- trix deposition, angiogenesis, and remodelling (16). However, chronic non-healing ulcers are trapped in an inflammatory cycle and fail to proceed to normal stages of wound healing, as the ulcer bed is phenotypically altered as a result of prolonged exposure to inflammatory cytokines, and bacterial toxins. These all contribute to cell 
Table 3. The mean number of anti-PCNA positive nuclei in connective tissue in each group within same time interval

\begin{tabular}{|c|c|c|c|c|c|}
\hline & & \multicolumn{4}{|c|}{ Mean of anti-PCNA positive nuclei in connective tissue } \\
\hline & & 3 days & 5 days & 7 days & 10 days \\
\hline Control & & $102.20 \pm 8.167$ & $126.20 \pm 32.561$ & $179.80 \pm 14.601$ & $198.80 \pm 4.76$ \\
\hline PRP & & $122.80 \pm 14.37$ & $259.40 \pm 26.26$ & $225.40 \pm 13.44$ & $218.00 \pm 5.00$ \\
\hline BMSCs & & $170.20 \pm 24.66$ & $221.40 \pm 35.82$ & $276.00 \pm 19.42$ & $224.20 \pm 10.18$ \\
\hline ANOVA & $\mathrm{F}$ & 20.68 & 23.28 & 45.02 & 17.37 \\
\hline Tukey HSD & p-value & 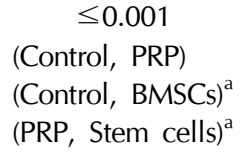 & $\begin{array}{l}\leq 0.001 \\
(\text { Control, PRP) } \\
\left(^{a}\right. \\
(\text { Control, BMSCs })^{a} \\
\text { (PRP, Stem cells) }\end{array}$ & $\begin{array}{l}\quad \leq 0.001 \\
(\text { Control, PRP) } \\
\left(^{\mathrm{a}}\right. \\
{\text { (Control, BMSCs })^{\mathrm{a}}}\end{array}$ & $\begin{array}{l}\quad \leq 0.001 \\
(\text { Control, PRP) } \\
(\text { Control, BMSCs) } \\
\text { (PRP, BMSCs) }\end{array}$ \\
\hline
\end{tabular}

a The mean difference is significant at $\mathrm{p} \leq 0.05$ level.

Values are given as mean $\pm \mathrm{SD}$, in $\mathrm{mm}^{2}$.

PRP: Platelet rich plasma, BMSCs: Bone marrow mesenchymal stem cells.

senescence and transform the normal progression of healing into a self-sustaining cycle of inflammation and injury (10).

In this study we induced chronic ulcers formation. As from a histopathologic view, acute ulcers are shallow ulcers or erosions. while, chronic ulcers are defined as deep tissue defects penetrating even beyond proper muscle layers, to which we did using the punch and further using the formocresol which provided chronic microenvironment to the wound $(13,14,17)$.

Researchers have been seeking novel alternative treatments that aim to accelerate the rate of healing, to improve its quality and achieve regenerative process rather than a repair orientated one, through replacing senescent resident cells and to re-establish the normal healing cascade (10). These alternative therapies include PRP and BMSCs, which both of them represent a biological pool of wide range of growth factors and cytokines that are essential for optimum wound healing $(5,6)$. In this study, we hypothesized that both remedies will have a beneficial effect on healing induced oral ulcers in rats and aimed to compare their effect.

Platelets is well known to contain growth factors, coagulation proteins, adhesion molecules, cell-activating molecules, cytokines, integrins, inflammatory molecules which are pre-synthesized and packaged into the $\alpha$-granules (18). Thus using PRP allowed for the releasing of a pool of highly concentrated different biologically active substances and signals derived from platelets $(19,20)$. For instance, using enzyme-linked immunosorbent assay, there was a 7 -fold increase in TGF- $\beta, 18$-fold increase in PDGF, a 1.9-fold increase in IGF-1and 4.6-fold increase in EGF in PRP compared with whole blood (21).

We found that using PRP accelerated clinical resolution of oral ulcers in comparison to control in all intervals except at the beginning and the end of the experiment. Although there was a gradual decrease in the ulcer size of the PRP group over the investigated intervals, the only statistical significance was reported between 5 to 7 days. This may be partially explained by the significantly increased proliferation rate of both epithelial and connective tissue cells observed at day 5 (22).

Histologically, we found that unlike the control the wounds of the PRP group exhibited signs of epithelial cells migration at the wound margin from day 3, until the wound was completely covered by a thin layer of stratified squamous epithelium with a thin keratin layer and flat rete ridges. This enhancement of proliferation and migration of basal and suprabasal epithelial cell was achieved by expanding the action of PDGF, TGF- $\beta$, EGF and KGF (19).

On day 5 and 7, the lamina propria of the PRP group displayed fine interlacing collagen fibres which were thickened by day 10. PRP contains elevated levels of FGF, PDGF and EGF that stimulate fibroblast proliferation (22), and high amount of TGF- $\beta 1$ that up-regulate expression of type I collagen, MMP-1 in fibroblasts and increases fibronectin and glycosaminoglycan synthesis (23). These combined factors were found to quicken the maturation of collagen, that can lead to an increase in the strength of wound tension (24).

Also, we observed numerous dilated blood vessels from the early stages of oral ulcer healing, to which may be attributed to the strong stimulant effect PRP has on capillary regeneration in wound healing (25). This effect is mediated via growth factors, such as VEGF, PDGF and IGF, to which that induce angiogenesis, and therefore increase the nutrition supply to the area and decrease the 
healing time (26). Furthermore, platelets release histamine and serotonin, which both function to increase capillary permeability, thus significantly allowing inflammatory cells to access the wound site (27).

All these released growth factors accelerate wound healing by various overlapping mechanisms such as stimulating angiogenesis, granulation tissue formation and epithelization (25).

Interestingly, PRP was found to boost the inflammatory phase of wound healing and hasten tissue debridement, by increasing the concentration of PDGF and TGF- $\beta$, to which are a chemotactic factor for neutrophils and monocytes (28). In addition, it contains soluble fibrinogen that modulates the activity of monocytes and macrophages and therefore mediates the transition between inflammatory and regenerative stages of injury response, breaking the viscous cycle of continue inflammation in non-healing ulcers (29).

Clinically, we found that unlike PRP group, there was a significant reduction in ulcer size between BMSCs and the control groups in all intervals. Also, we found that BMSCs group yielded better clinical resolution at the beginning and at the end of the intervals. However, there was no significant reduction between both groups in day 5 or 7 . This is may be attributed to the higher cellular proliferation rate of both epithelial and connective tissue cells scored on day 5 by the PRP group. Although there is no clear explanation of such finding, we speculate that this may be due to the fact that PRP acts as a reservoir for concentrated amount of growth factors that are released at the same time. However, once this robust amount of factors is exhausted, there is no renewed or sustained source for them (30).

On histological examination, we found that the ulcer of BMSCs group progressively healed in a favourable manner as epithelial proliferation and migration at the wound margin was evidenced, by increased mitotic figures in the epithelial cells from day 3. This migration continued until ulcer closure with almost complete reepithelization. The epithelium displayed maturation and moderate thickness of keratinisation. These findings are consistent with the steady increase of epithelial cells proliferation noticed from the beginning of the experimental period till its end. This is may be explained by the following first; the paracrine effect of the transplanted stem cells through growth factors and cytokines, which they release to increase epithelial cells proliferation $(31,32)$ and to make the microenvironment more appropriate for the repair of injury (33). Second; by transdifferentiating into keratinocytes directly $(34,35)$. Third; MSCs were found to be immunor- eactive to fibronectin, which suggested that MSCs may interact with keratinocytes to accelerate wound healing (36).

Also, we observed that from day 3 , the underlying lamina propria displayed moderate amount of collagen fibres and numerous variable sized blood vessels. The organization and maturation of collagen fibres proceeded through time intervals rapidly, until by the end of the experiment. The connective tissue started to regain its normal architecture with more organized and mature collagen fibres, many fibroblasts, high vascularity and mild inflammatory cells infiltration. This is in consistent with other studies that have found that MSCs was more effective in treating oral mucositis and ulcers by promoting the organization and deposition of collagen $(17,37)$. The high vasculature seen in the BMSCs group throughout the experimental period, compared to control group could be explained through previous studies, which state that MSCs can acquire phenotypic characteristics of vascular endothelial cells (36). In addition to this, it was found that MSCs express mRNAs for various angiogenic factors such as VEGF, which increase angiogenesis and contributes to the observed clinical improvement (17).

Collectively, we found that at the end of our experimental period, stem cell group yielded better results than PRP group. This was presented clinically in the faster rate of ulcer healing. Histologically, the stem cells group showed better tissue organization and maturation and histochemically, by a significantly higher cellular proliferation rate in most intervals. This is can be explained as although they both share the following characteristics; i) the boosting of inflammatory response, ii) Antimicrobial effect, iii) releasing growth factor, iv) increasing both cellular and capillary proliferation. MSCs uniquely have more beneficial properties that evokes faster tissue regeneration and not just simple wound repair (11). First; MSCs possess a high expression of several pro-healing genes that ensure growth factors and cytokines production for a more extended period of time (38). Secondly; they can transdifferentiation into different cell types needed for tissue regeneration. Thirdly; MSCs revealed a powerful chemotactic migration toward epidermal keratinocytes, dermal fibroblasts and endothelial cells (39). Finally; it is noteworthy that MSCs increase production of type III collagen needed specifically in tissue repair (40).

Several limitations are inherent in this study, we used healthy rats even though oral ulcers are more prevalent in local or systemic immunosuppressed patients. Moreover, this study was limited to male rats only, therefore it didn't show the impact of sex hormones on the wound healing process and fluctuations, concerning their levels during 
the reproductive cycle of female rats. In addition, we used $8 \sim 10$ weeks old rat, that are fairly young rats and have faster healing abilities. This might explain the short time intervals that we used in the experiment based on our pilot study, therefore proving it necessary to demonstrate differences as rats advances in age. Furthermore, it would have been beneficial to quantitatively assess histological data, despite present study focusing on what influences the rate and quality of clean wound repair.

Another limitation in the possibility of locally administered stem cell dying before being significatly differentiate due to oxygen limitation, this was overcomed by injecting large number of cells $\left(1 \times 10^{6}\right)$ that was injected at multiple points around the ulcer. We do not know whether the transplanted MSCs differentiated into functional cells that replaced the damaged cells in the tissue or that they remained as they were. Further study would be needed to fully clarify the fate of the MSCs in the mucosa. More studies should aim to create a gold standard protocol for PRP generation and characterization, optimal concentration of PRP, optimal timing of the injection, its persistence over time and on the consequent effects on the final outcome for each specific application. Also, further studies should focus on the impact of local wound microenvironment on MSCs engraftment, in addition long-term systemic effects of MSC-based therapy.

In conclusion, this study suggests that both PRP and BMSCs can accelerate the healing of induced oral ulcers in rats, however BMSCs yielded improved clinical and histological results. These findings suggest that one day MSCs can be a fast alternative therapy for non healed chronic oral ulcers that standard remedies cannot heal. Hopefully with the emergence of new MSCs subpopulations, (that are effortlessly isolated in a quicker, less intrusive way and are better characterized) to be selectively applied to specific disorder which may result in an enhanced therapeutic effect.

\section{Potential Conflict of Interest}

The authors have no conflicting financial interest.

\section{References}

1. Schneider LC, Schneider AE. Diagnosis of oral ulcers. Mt Sinai J Med 1998;65:383-387

2. Scully C, Shotts R. ABC of oral health. Mouth ulcers and other causes of orofacial soreness and pain. BMJ 2000;321: $162-165$

3. Alamoudi NM, El Ashiry EA, Farsi NM, El Derwi DA, Atta HM. Treatment of oral ulcers in dogs using adipose tissue-derived mesenchymal stem cells. J Clin Pediatr Dent 2014;38:215-222

4. Werner S, Grose R. Regulation of wound healing by growth factors and cytokines. Physiol Rev 2003;83:835-870

5. Arora NS, Ramanayake T, Ren YF, Romanos GE. Plateletrich plasma: a literature review. Implant Dent 2009;18:303310

6. Hocking AM, Gibran NS. Mesenchymal stem cells: paracrine signaling and differentiation during cutaneous wound repair. Exp Cell Res 2010;316:2213-2219

7. Nikolidakis D, Jansen JA. The biology of platelet-rich plasma and its application in oral surgery: literature review. Tissue Eng Part B Rev 2008;14:249-258

8. Crovetti G, Martinelli G, Issi M, Barone M, Guizzardi M, Campanati B, Moroni M, Carabelli A. Platelet gel for healing cutaneous chronic wounds. Transfus Apher Sci 2004; 30:145-151

9. Yamada Y, Ueda $M$, Naiki T, Takahashi $M$, Hata $K$, Nagasaka T. Autogenous injectable bone for regeneration with mesenchymal stem cells and platelet-rich plasma: tissue-engineered bone regeneration. Tissue Eng 2004;10:955964

10. Hanson SE, Bentz ML, Hematti P. Mesenchymal stem cell therapy for nonhealing cutaneous wounds. Plast Reconstr Surg 2010;125:510-516

11. Marfia G, Navone SE, Di Vito C, Ughi N, Tabano S, Miozzo M, Tremolada C, Bolla G, Crotti C, Ingegnoli F, Rampini P, Riboni L, Gualtierotti R, Campanella R. Mesenchymal stem cells: potential for therapy and treatment of chronic non-healing skin wounds. Organogenesis 2015; 11:183-206

12. National Research Council (US) Committee for the Update of the Guide for the Care and Use of Laboratory Animals. Guide for the care and use of laboratory animals. 8th ed. Washington: National Academy Press; 2011. 41-196

13. Duarte CM, Quirino MR, Patrocínio MC, Anbinder AL. Effects of Chamomilla recutita (L.) on oral wound healing in rats. Med Oral Patol Oral Cir Bucal 2011;16:e716-e721

14. de Carvalho FB, Andrade AS, Rasquin LC, de Castro IV, Cangussu MC, Pinheiro AL, dos Santos JN. Effect of laser $(\lambda 660 \mathrm{~nm})$ and LED $(\lambda 630 \mathrm{~nm})$ photobiomodulation on formocresol-induced oral ulcers: a clinical and histological study on rodents. Lasers Med Sci 2015;30:389-396

15. Falanga V, Iwamoto S, Chartier M, Yufit T, Butmarc J, Kouttab N, Shrayer D, Carson P. Autologous bone marrow-derived cultured mesenchymal stem cells delivered in a fibrin spray accelerate healing in murine and human cutaneous wounds. Tissue Eng 2007;13:1299-1312

16. Eming SA, Martin P, Tomic-Canic M. Wound repair and regeneration: mechanisms, signaling, and translation. Sci Transl Med 2014;6:265sr6

17. El-Menoufy H, Aly LA, Aziz MT, Atta HM, Roshdy NK, Rashed LA, Sabry D. The role of bone marrow-derived mesenchymal stem cells in treating formocresol induced oral ulcers in dogs. J Oral Pathol Med 2010;39:281-289

18. Anitua E, Andia I, Ardanza B, Nurden P, Nurden AT. 
Autologous platelets as a source of proteins for healing and tissue regeneration. Thromb Haemost 2004;91:4-15

19. Aiba-Kojima E, Tsuno $\mathrm{NH}$, Inoue $\mathrm{K}$, Matsumoto $\mathrm{D}$, Shigeura T, Sato T, Suga H, Kato H, Nagase T, Gonda K, Koshima I, Takahashi K, Yoshimura K. Characterization of wound drainage fluids as a source of soluble factors associated with wound healing: comparison with platelet-rich plasma and potential use in cell culture. Wound Repair Regen 2007;15:511-520

20. Everts PA, Brown Mahoney C, Hoffmann JJ, Schönberger JP, Box HA, van Zundert A, Knape JT. Platelet-rich plasma preparation using three devices: implications for platelet activation and platelet growth factor release. Growth Factors 2006;24:165-171

21. Fréchette JP, Martineau I, Gagnon G. Platelet-rich plasmas: growth factor content and roles in wound healing. J Dent Res 2005;84:434-439

22. Sinno H, Prakash S. Complements and the wound healing cascade: an updated review. Plast Surg Int 2013;2013: 146764

23. Mirastschijski U, Jokuszies A, Vogt PM. Skin wound healing: repair biology, wound and scar treatment. In: Warren R, Neligan P, editors. Plastic surgery. 3rd ed. Philadelphia, PA: Elsevier Saunders; 2013. 271-273

24. Carter CA, Jolly DG, Worden CE Sr, Hendren DG, Kane CJ. Platelet-rich plasma gel promotes differentiation and regeneration during equine wound healing. Exp Mol Pathol 2003;74:244-255

25. Lindeboom JA, Mathura KR, Aartman IH, Kroon FH, Milstein DM, Ince C. Influence of the application of platelet-enriched plasma in oral mucosal wound healing. Clin Oral Implants Res 2007;18:133-139

26. Rozman P, Bolta Z. Use of platelet growth factors in treating wounds and soft-tissue injuries. Acta Dermatovenerol Alp Pannonica Adriat 2007;16:156-165

27. Lacci KM, Dardik A. Platelet-rich plasma: support for its use in wound healing. Yale J Biol Med 2010;83:1-9

28. DeRossi R, Coelho AC, Mello GS, Frazílio FO, Leal CR, Facco GG, Brum KB. Effects of platelet-rich plasma gel on skin healing in surgical wound in horses. Acta Cir Bras 2009;24:276-281

29. Wasterlain AS, Braun HJ, Dragoo JL. Contents and formulations of platelet rich plasma. In: Maffulli $\mathrm{N}$, editor. Platelet rich plasma in musculoskeletal practice. London:
Springer-Verlag; 2016. 1-29

30. Arnoczky SP, Sheibani-Rad S. The basic science of platelet-rich plasma (PRP): what clinicians need to know. Sports Med Arthrosc Rev 2013;21:180-185

31. Zhang Q, Nguyen AL, Shi S, Hill C, Wilder-Smith P, Krasieva TB, Le AD. Three-dimensional spheroid culture of human gingiva-derived mesenchymal stem cells enhances mitigation of chemotherapy-induced oral mucositis. Stem Cells Dev 2012;21:937-947

32. I T, Sumita Y, Minamizato T, Umebayashi M, Liu Y, Tran $\mathrm{SD}$, Asahina I. Bone marrow-derived cell therapy for oral mucosal repair after irradiation. J Dent Res 2014;93:813820

33. Chen L, Tredget EE, Wu PY, Wu Y. Paracrine factors of mesenchymal stem cells recruit macrophages and endothelial lineage cells and enhance wound healing. PLoS One 2008;3:e1886

34. Sasaki M, Abe R, Fujita Y, Ando S, Inokuma D, Shimizu H. Mesenchymal stem cells are recruited into wounded skin and contribute to wound repair by transdifferentiation into multiple skin cell type. J Immunol 2008;180:2581-2587

35. Lin CY, Lee BS, Liao CC, Cheng WJ, Chang FM, Chen $\mathrm{MH}$. Transdifferentiation of bone marrow stem cells into acinar cells using a double chamber system. J Formos Med Assoc 2007;106:1-7

36. Fu X, Fang L, Li X, Cheng B, Sheng Z. Enhanced woundhealing quality with bone marrow mesenchymal stem cells autografting after skin injury. Wound Repair Regen 2006; 14:325-335

37. Jin IG, Kim JH, Wu HG, Hwang SJ. Effect of mesenchymal stem cells and platelet-derived growth factor on the healing of radiation induced ulcer in rats. Tissue Eng Regen Med 2016;13:78-90

38. An Y, wei W, Jing H, Ming L, Liu S, Jin Y. Bone marrow mesenchymal stem cell aggregate: an optimal cell therapy for full-layer cutaneous wound vascularization and regeneration. Sci Rep 2015;5:17036

39. Akino K, Mineda T, Akita S. Early cellular changes of human mesenchymal stem cells and their interaction with other cells. Wound Repair Regen 2005;13:434-440

40. Fathke C, Wilson L, Hutter J, Kapoor V, Smith A, Hocking A, Isik F. Contribution of bone marrow-derived cells to skin: collagen deposition and wound repair. Stem Cells 2004;22:812-822 